\title{
ANALISIS POTENSI SEKTOR POTENSI PERTANIAN DI KABUPATEN KEDIRI TAHUN 2010-2014
}

\author{
Oleh: \\ Abdurrahman Rasyid \\ Program Nasional Pemberdayaan Masyarakat Pedesaan (PNPM) Kepung - Kediri \\ E-mail: Rasyid9222@yahoo.com
}

\begin{abstract}
The purpose of this study refers to the content and formulation of research problems, namely: to identify the structure of the economy in Kediri, analyzing knowing what economic sectors into competitive advantage and specialization in Kediri, analyzing whether there is an increase or decrease. The analysis tool used is: 1). Sector contribution (contribution) to the GDP, 2). Location Quotient (quotient Area), 3). Shift-Share Analysis: 4). Analysis MRP. The results of the analysis using the contributions show 1) Average sectoral contribution to the GDP the highest rates in Kediri is found in the agriculture sector and continue to decline. For the lowest contribution rate of the economic sector to the GDP at constant prices in Kediri are sectors Electricity, Gas \& Water 2014 with the value of an average contribution amounting The results showed that the determination of a sector basis Basis sector is still dominated by agriculture sector and mining sector \& Excavation which is as Primary Sector
\end{abstract}

Keyword: Profitability (ROA), CAR, NPL, LDR, Size Bank, and Multiple Linear Regression.

\begin{abstract}
ABSTRAK
Tujuan penelitian ini mengacu pada isi dan rumusan masalah penelitian yaitu : untuk mengidentifikasi struktur perekonomian di Kabupaten Kediri, menganalisa mengetahui sektor ekonomi apa yang menjadi unggulan kompetitif dan spesialisasi di Kabupaten Kediri, menganalisa apakah terjadi kenaikan atau penurunan. Alat analisis yang digunakan adalah: 1). Sumbangan sektor (kontribusi) terhadap PDRB, 2). Location Quotient (Kuosien Lokasi), 3). Analisis Shift-Share: 4). Analisis MRP. Hasil analisis menggunakan metode kontribusi menunjukkan 1) Rata-rata kontribusi sektoral terhadap PDRB angka tertinggi pada Kabupaten Kediri yaitu terdapat pada sektor Pertanian dan terus menurun Untuk angka kontribusi terendah dari sektor ekonomi terhadap PDRB atas dasar harga konstan di Kabupaten Kediri adalah sektor Listrik, Gas \& Air Bersih dengan tahun 2014 dengan nilai kontribusi rata-rata sebesar. Hasil penentuan sektor basis menunjukkan bahwa Sektor Basis masih didominasi sektor Pertanian dan sektor Pertambangan \& Penggalian yang merupakan sebagai Sektor Primer.
\end{abstract}

Kata Kunci : Profitabilitas (ROA), CAR, NPL, LDR, Size Bank, dan Regresi Linier Berganda. 


\section{PENDAHULUAN}

Pembangunan ekonomi daerah merupakan suatu proses dimana Pemerintah Daerah dan masyarakat mengelola sumberdaya-sumberdaya yang ada, dengan menjalin pola-pola kemitraan antara Pemerintah Daerah dan pihak swasta guna penciptaan lapangan kerja, serta dapat merangsang pertumbuhan ekonomi di Daerah yang bersangkutan. (Suparmoko, 2002).

Dalam proses Perencanaan Daerah, analisis fungsi merupakan suatu alat yang efektif untuk melihat kerangka-kerangka umum seperti tersebut diatas, dan secara efektif dapat digunakan untuk melihat dan sebagai instrumen kegiatan ekonomi masyarakat yang dikonsentrasikan dalam suatu area tertentu pada lingkungan wilayah pembangunan, sehingga dapat memudahkan para perencana untuk menentukan prioritas-prioritas yang mendorong masyarakat untuk memperoleh fasilitas pelayanan secara mudah.

Keberhasilan pembangunan ekonomi Daerah, sangat ditentukan oleh sasaran pembangunan yang berlandaskan pada upaya meningkatkan pertumbuhan ekonomi yang mampu menciptakan lapangan kerja secara optimal dari segi jumlah, produktivitas dan efisien.

Dalam penentuan kebijakan, haruslah memperhitungkan kondisi internal maupun perkembangan eksternal. Perbedaan kondisi internal dan eksternal hanyalah pada jangkauan suatu wilayah, dimana kondisi internal meliputi wilayah daerah/regional, sedangkan kondisi eksternal meliputi pada wilayah nasional. Perbaikan ekonomi bukan hanya dilakukan oleh pemerintah pusat, tetapi pemerintah daerah juga mengupayakan perbaikan tersebut, baik perbaikan secara makro ataupun mikro.

Pertumbuhan ekonomi wilayah adalah pertambahan tingkat pendapatan masyarakat secara keseluruhan yang terjadi di wilayah tersebut, yaitu: kenaikan seluruh nilai tambah (value added) yang terjadi. Indikator perhitungan pendapatan wilayah pada awalnya dibuat dalam harga berlaku. Namun agar dapat melihat pertambahan dari kurun waktu ke kurun waktu berikutnya, harus dinyatakan dalam nilai riil, artinya dinyatakan dalam 
harga konstan. Biasanya Badan

Pusat Statisik dalam menerbitkan laporan pendapatan regional tersedia angka dalam harga berlaku dan harga konstan.

Pendapatan wilayah menggambarkan balas jasa bagi faktor-faktor aktivitas produksi di daerah tersebut (tanah, modal, tenaga kerja, dan teknologi), yang berarti secara essensial dapat menggambarkan kondisi kemakmuran daerah tersebut. Kemakmuran suatu wilayah selain ditentukan oleh besarnya nilai tambah yang tercipta di wilayah tersebut juga oleh seberapa besar terjadi transfer payment, yaitu bagian pendapatan yang mengalir ke luar wilayah atau mendapat aliran dana dari luar wilayah.

Pertumbuhan ekonomi adalah suatu proses kenaikan output perkapita dalam jangka panjang". Jadi, persentase pertambahan output haruslah lebih tinggi dari persentase pertambahan jumlah penduduk dan ada kecenderungan dalam jangka panjang bahwa pertumbuhan itu akan berlanjut.

Selain itu menurut pendapat para ahli ekonomi yang membuat definisi yang lebih eksplisit, yaitu: bahwa pertumbuhan itu haruslah bersumber dari proses intern perekonomian tersebut. Dalam penggunaan secara umum, istilah pertumbuhan ekonomi digunakan untuk menyatakan kondisi perkembangan ekonomi di Negara berkembang. Akhirnya, suatu perekonomian baru dapat dinyatakan dalam keadaan berkembang apabila pendapatan perkapita menunjukkan kecenderungan (trend) jangka panjang yang meningkat. Pada aspek ini tidak berarti bahwa pendapatan perkapita harus mengalami kenaikan terus menerus. (Sukirno, 2004: 14).

Pada dasarnya pembangunan ekonomi mempunyai empat dimensi pokok yaitu:

1) Pertumbuhan,

2) Penanggulangan kemiskinan,

3) Perubahan atau transformasi ekonomi, dan

4) Keberlanjutan pembangunan dari masyarakat agraris menjadi masyarakat industri.

Transformasi struktural merupakan indikator penting dari peningkatan dan kesinambungan 
pertumbuhan serta penanggulangan kemiskinan, sekaligus pendukung bagi keberlanjutan pembangunan itu sendiri.

Proses terjadinya perubahan struktur perekonomian ditandai dengan beberapa hal yaitu:

1) Menurunnya pangsa sektor primer (pertanian),

2) Meningkatnya pangsa sektor sekunder (industri), dan

3) Pangsa sektor tersier (jasa) juga memberikan kontribusi yang meningkat sejalan dengan pertumbuhan ekonomi. Sejarah pertumbuhan ekonomi negaranegara maju menunjukkan pentingnya pengaruh tingkat perkembangan struktural dan sektoral yang tinggi dalam proses pertumbuhan ekonomi. Beberapa komponen yang utama dari proses perubahan struktural tersebut antara lain mencakup pergeseran bertahap dari aktivitas sektor pertanian ke sektor non pertanian

Pertumbuhan ekonomi telah mengakibatkan perubahan struktur perekonomian. Transformasi struktural sendiri merupakan proses perubahan struktur perekonomian dari sektor pertanian ke sektor industri, perdagangan dan jasa, dimana masing-masing perekonomian akan mengalami transformasi yang berbeda-beda. Pada umumnya dengan transformasi yang terjadi di Negara sedang berkembang adalah transformasi dari sektor pertanian ke sektor industri. Perubahan struktur ekonomi atau transformasi ekonomi dari tradisional menjadi modern secara umum dapat didefinisikan sebagai suatu perubahan dalam ekonomi yang berkaitan dengan komposisi penyerapan tenaga kerja, produksi, perdagangan, dan faktorfaktor lain yang diperlukan secara terus menerus untuk meningkatkan pendapatan dan kesejahteraan sosial melalui peningkatan pendapatan perkapita.

Struktur ekonomi daerah berdampak pada peningkatan sektorsektor perekonomian lainnya yang saling berkaitan. Suatu daerah dapat dikatakan maju apabila ditunjang dari segi pengetahuan masyarakat yang tinggi, adanya sumber daya alam yang cukup memadai yang dikelola oleh sumber daya manusia yang mempunyai potensi besar guna 
tercapainya kemajuan pembangunan daerah. Proses industrialisasi diharapkan dapat menanggulangi permasalahan peningkatan kebutuhan lapangan pekerjaan.

Salah satu indikator keberlangsungan pembangunan ekonomi suatu daerah adalah laju pertumbuhan ekonomi. Statistik pertumbuhan ekonomi merupakan salah satu derivatif dari statistik Produk Domestik Regional Bruto (PDRB). Bila kita melakukan data plotting terhadap angka pertumbuhan ekonomi Kabupaten Kediri, maka akan kita ketahui trend yang terus meningkat. Walaupun terus menunjukkan angka peningkatan, namun laju percepatan pembangunan tiap tahun selalu fluktuatif dan pertumbuhan ekonomi Kabupaten Kediri tidak pernah melampaui pertumbuhan ekonomi pada tingkat Provinsi apalagi Nasional.

Sektor Industri yang diharapkan mampu sebagai substitute sektor atau sektor pengganti, perkembangannya masih jauh dari harapan. Kecenderungan pertumbuhan sektor industri sebenarnya cukup menjanjikan.
Namun karena beberapa hal, sektor industri hingga tahun ini belum berhasil menjadi substitute sektor, diantaranya adalah sebagai berikut:

1) Kabupaten Kediri relative jauh dari bandara dan pelabuhan.

2) Iklim usaha dan perijinan yang belum kondusif.

3) Upah buruh yang relative mahal (Kabupaten Kediri termasuk ring 2)

4) Lahan yang masih prospektif untuk pertanian.

Berdasarkan dari subtansi latar belakang diatas, maka secara spesifik akan dibahas dan ditinjau secara empiris mengenai kondisi perekonomian di Kabupaten Kediri tersebut melalui penelitian ini dengan judul. "Analisis Potensi Sektor Pertanian di Kabupaten Kediri Tahun 2010-2014 “

\section{METODE PENELITIAN}

Jenis penelitian yang digunakan adalah deskriptif kuantitatif yaitu metode analisa data dengan menggunakan data dalam bentuk angka-angka atau nilai dari bentuk data kemudian dianalisa dengan menambahkan keterangan berupa 
kalimat-kalimat untuk menerangkan data kuantitatif.

\section{Jenis Dan Sumber Data}

Data yang dikumpulkan dalam penelitian ini merupakan data sekunder yang diperoleh dari Sumber data Instansi-instansi pemerintahan seperti BPS (Badan Pusat Statistik) Kabupaten Kediri, Badan Perencanaan Pembangunan Derah kediri (BAPPEDA) Kabupaten Kediri serta instansiinstansi lain yang terkait.

Data dalam penelitian ini adalah data panel dari tahun 20112014, data tersebut digunakan data sekunder melalui metode dokumentasi berupa data PDRB Kabupaten kediri dan PDRB Propinsi jawa timur Tengah tahun 2010-2014 (data terbaru) atas dasar harga berlaku dan atas dasar harga konstan yang bersumber dari dokumentasi BPS. Metode pengambilan sampel menggunakan purposive sampel, purposive sampel adalah pengambilan secara sengaja sesuai dengan persyaratan sampel yang diperlukan.

Metode dokumentasi berupa data PDRB Kabupaten kediri dan PDRB Propinsi jawa timur Tengah tahun 2010-2014 (data terbaru) atas dasar harga berlaku dan atas dasar harga konstan yang bersumber dari dokumentasi BPS.

\section{Analisis LQ}

Teknik ini membandingkan tentang besarnya peranan suatu sektor disuatu daerah terhadap besarnya peranan sektor tersebut ditingkat nasional. Teknik ini digunakan untuk mengidentifikasi potensi internal yang dimiliki daerah tersebut yaitu sektor basis dan yang merupakan sektor basis (non basis).

\section{Analisis Shift Share}

Analisis ini pada dasarnya membahas hubungan antara pertumbuhan wilayah dan struktur ekonomi wilayah. Dengan pendekatan analisis ini dapat ditentukan kinerja atau produktifitas kerja perekonomian serta untuk mengidentifikasikan sektor unggul daerah dengan membandingkannya dengan daerah yang lebih besar (Regional atau Nasional) digunakan pula untuk melihat pertumbuhan PDRB dari sektor-sektor yang dimiliki baik pengaruh dari internal (faktor lokasisonal) maupun pengaruh eksternal (struktur industri) dan alat analisis ini juga 
digunakan untuk melengkapi analisis LQ yang telah dilakukan.

PEMBAHASAN

Sektor unggulan Sektor Pertanian

\section{di Kabupaten Kediri}

Analisis Location Quotient (LQ) digunakan untuk mengetahui sektor-sektor ekonomi dalam PDRB yang dapat digolongkan ke dalam sektor basis dan non basis. LQ merupakan suatu perbandingan tentang besarnya peranan suatu sektor di Kediri terhadap besarnya peranan sektor tersebut di tingkat Provinsi Jawa Timur secara keseluruhan. (Annisa Nurfatimah, 2013)

Nilai LQ (Location Quotient) > 1 berarti bahwa peranan suatu sektor di Kabupaten lebih dominan dibandingkan sektor di tingkat Provinsi dan sebagai petunjuk bahwa Kabupaten surplus akan produk sektor tersebut.

Sebaliknya bila nilai LQ $<1$ berarti peranan sektor tersebut lebih kecil di Kabupaten dibandingkan peranannya di tingkat Provinsi. Nilai LQ (Location Quotient) dapat dikatakan sebagai petunjuk untuk dijadikan dasar untuk menentukan sektor yang potensial untuk dikembangkan.

Karena sektor tersebut tidak saja dapat memenuhi kebutuhan di dalam daerah, akan tetapi dapat juga memenuhi kebutuhan di daerah lain atau surplus.

Tabel 1. Perhitungan Location Quotient sektor pertanian di Kabupaten Kediri tahun 2010-2014

\begin{tabular}{lcccccc}
\hline Tahun & 2010 & 2011 & 2012 & 2013 & 2014 & Rata-Rata \\
\hline Location equatin & 2,0112 & 1,9787 & 1,9997 & 1,9569 &, 9591 & 1,9811 \\
\hline
\end{tabular}

Sumber : BPS Kabupaten Kabupaten Kediri 2010-2014

\section{Gambar 1. Location Quotient sektor pertanian di Kabupaten Kediri tahun} 2010-2014

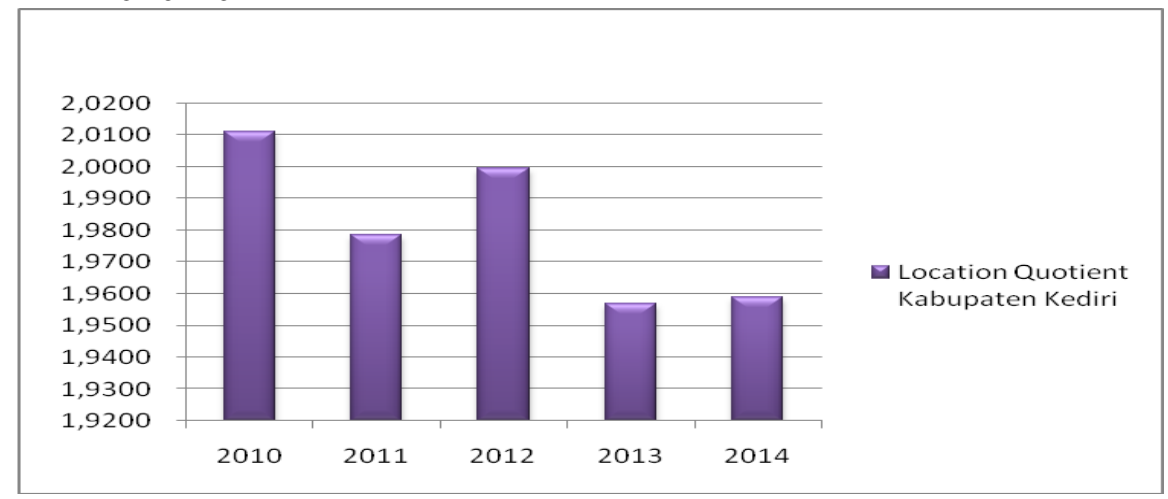


Sumber: BPS 2016 (Data Diolah)

Nilai LQ (Location Quotient) milik kabupaten Kediri mengalami fluktiasi selama lima tahun terakhir. Nilai LQ (Location Quotient) > 1 berarti bahwa peranan suatu sektor di Kabupaten lebih dominan dibandingkan sektor di tingkat Provinsi dan sebagai petunjuk bahwa Kabupaten surplus akan produk sektor tersebut. Sehingga Kabupaten Kediri surplus akan produk pertanian yang dihasilkan karena nilai LQ selama lima tahun diatas 1 .

Analisis Shift Share digunakan untuk mengetahui proses pertumbuhan ekonomi Kabupaten Kediri dikaitkan dengan perekonomian daerah yang menjadi referensi, yaitu Provinsi Jawa Timur. Analisis Shift Share dalam penelitian ini menggunakan variabel pendapatan, yaitu PDRB untuk menguraikan pertumbuhan ekonomi Kabupaten

Kediri. (Suparmoko,2002)

Pertumbuhan PDRB total (Y) dapat diuraikan menjadi komponen shift dan komponen share, yaitu:
1) Komponen Provincial Share (PS) adalah banyaknya pertambahan PDRB Kabupaten Kediri seandainya pertumbuhannya sama dengan laju pertumbuhan PDRB Provinsi Jawa Timur selama periode studi.

2) Komponen Proportional Shift (P), mengukur besarnya net shift Kabupaten Kediri yang diakibatkan oleh komposisi sektor-sektor PDRB Kabupaten Kediri yang berubah. Apabila $\mathrm{P}>0$, artinya Kabupaten Kediri berspesialisasi pada sektorsektor yang pada tingkat Provinsi Jawa Timur tumbuh relatif cepat dan apabila $\mathrm{P}<0$, berarti Kabupaten Kediri berspesialisasi pada sektorsektor di tingkat Provinsi Jawa Timur pertumbuhannya lebih lambat atau sedang menurun.

3) Komponen Differential Shift (D), mengukur besarnya net shift yang diakibatkan oleh sektor-sektor tertentu yang tumbuh lebih cepat atau lebih lambat di Kabupaten Kediri 
dibandingkan dengan Provinsi

Jawa Timur yang disebabkan

oleh faktor-faktor lokasional intern, seperti sumber daya yang baik akan mempunyai Differential Shift Component positif (D > 0), sebaliknya apabila secara lokasional tidak menguntungkan akan mempunyai Differential Shift Component yang negatif (D < $0)$.

4) Nilai Differential Shift Component

mengindikasikan bahwasektor tersebut memberikan kontribusi yang menguntungkan baik untuk wilayah kabupaten maupun wilayah provinsi.

5) Analisis penentuan sektor ekonomi strategis dan memiliki keunggulan untuk dikembangkan dengan tujuan untuk memacu laju pertumbuhan Kabupaten Kediri. Untuk mengetahui sektor spesialisasi daerah serta pertumbuhannya digunakan komponen Provincial Share (PS), Proportional Shift (P), dan Differential Shift (D).
6) Nilai $P$ positif, berarti perekonomian Kabupaten Kediri berspesialisasi pada sektor yang sama yang tumbuh cepat pada perekonomian Provinsi Jawa Timur. Sebaliknya apabila nilai $\mathrm{P}$ negatif, berarti perekonomian Kabupaten Kediri berspesialisasi pada sektor yang sama dan tumbuh lambat pada perekonomian Provinsi Jawa Timur.

Sektor-sektor yang memiliki nilai komponen pertumbuhan proporsional positif, yaitu sektor pertanian, sektor bangunan dan konstruksi, sektor perdagangan, hotel dan restoran, sektor pengangkutan dan komunikasi, dan sektor jasa-jasa. Sedangkan sektorsektor yang mempunyai nilai komponen pertumbuhan proporsional negative, yaitu sektor pertambangan dan penggalian, sektor industri pengolahan, dan sektor bank dan lembaga keuangan lainnya. 
Tabel 2. Analisis Shift ShareKabupaten Kediri periode tahun 2010-2014

\begin{tabular}{|c|c|c|c|c|}
\hline Lapangan Usaha & $\begin{array}{l}\text { Provincial } \\
\text { Share (PS) }\end{array}$ & $\begin{array}{l}\text { Proportional } \\
\text { Shift (P) }\end{array}$ & $\begin{array}{l}\text { Different Shift } \\
\text { (D) }\end{array}$ & Total (Y) \\
\hline Pertanian & $3.694,09$ & $219.132,84$ & $64.729,88$ & $287.556,81$ \\
\hline $\begin{array}{ll}\text { Pertambangan } & \& \\
\text { Penggalian } & \\
\end{array}$ & $50.056,00$ & $(4.979 .719,43)$ & $(2.416 .966,08)$ & $(7.346 .629,51)$ \\
\hline Industri & $2.063,36$ & $(127.930,47)$ & $(142.976,08)$ & $(268.843,19)$ \\
\hline Listrik dan Gas & 17,75 & $3.852,87$ & $(3.359,09)$ & 511,53 \\
\hline $\begin{array}{l}\text { Air, Pengelolaan } \\
\text { Sampah \& limbah }\end{array}$ & $1.960,19$ & $(121.533,94)$ & $(135.827,28)$ & $(255.401,03)$ \\
\hline Konstruksi & 267,69 & $13.861,19$ & $56.847,05$ & $70.975,92$ \\
\hline $\begin{array}{ll}\text { Perdagangan } & \text { Besar } \\
\text { dan Eceran } & \\
\end{array}$ & $1.862,18$ & $(115.457,25)$ & $(129.035,91)$ & $(242.630,98)$ \\
\hline $\begin{array}{ll}\text { Transportasi } & \text { dan } \\
\text { Pergudangan } & \\
\end{array}$ & 901,26 & $128.270,95$ & $(88.993,21)$ & $40.179,00$ \\
\hline $\begin{array}{l}\text { Penyediaan } \\
\text { Akomodasi dan } \\
\text { Makan Minum }\end{array}$ & $1.540,11$ & $114.473,84$ & $(102.163,36)$ & $13.850,58$ \\
\hline $\begin{array}{ll}\text { Informasi } & \text { dan } \\
\text { Komunikasi } & \\
\end{array}$ & 15,97 & $3.467,59$ & $(3.023,18)$ & 460,38 \\
\hline $\begin{array}{l}\text { Jasa Keuangan dan } \\
\text { Asuransi }\end{array}$ & 57,42 & $(68.565,75)$ & $81.426,82$ & $12.918,49$ \\
\hline Real Estate & $55.061,60$ & $(5.477 .691,37)$ & $(2.658 .662,69)$ & $(8.081 .292,46)$ \\
\hline Jasa Perusahaan & $2.269,70$ & $(140.723,51)$ & $(157.273,69)$ & $(295.727,51)$ \\
\hline Jasa Jasa & 481,26 & $153.952,22$ & $(143.661,37)$ & $10.772,11$ \\
\hline Jumlah & $120.248,57$ & $(10.394 .610,22)$ & $(5.778 .938,19)$ & $\begin{array}{l}(16.053 .299,84 \\
)\end{array}$ \\
\hline
\end{tabular}

Sumber : BPS Kabupaten Kabupaten Kediri 2010-2014

Nilai Differential Shift (D) dibandingkan sektor yang sama di sektor perekonomian Kabupaten tingkat Provinsi Jawa Timur.

Kediri selama periode tahun 2010-

Sedangkan nilai D negatif, 2014 ada yang positif dan negatif. berarti sektor tersebut tumbuh lebih Nilai D positif, berarti bahwa lambat dibandingkan sektor yang terdapat sektor ekonomi Kabupaten sama di tingkat Provinsi Jawa Kediri tumbuh lebih cepat Timur. Ada tiga sektor perekonomian Kabupaten Kediri 
yang memilik nilai D Positif yaitu sektor pertanian, konstruksi dan jasa keuangan dan asuransi.

Ketiga sektor tersebut merupakan sektor yang pertumbuhannya cepat, sehingga berpotensi untuk dikembangkan dalam memacu pertumbuhan PDRB Kabupaten. Kediri. Sedangkan sektor - sektor lainnya, yaitu sektor pertambangan dan penggalian, industri , listrik dan gas, air pengolahan sampah dan limbah, perdagangan besar dan eceran, transportasi dan pergudangan, penyedia akomodasi dan makanan, informasi dan komunikasi, real estate, jasa perusahaan serta jasajasa memiliki nilai $D$ negatif, sehingga sektor-sektor tersebut pertumbuhannya lambat.

Kedua komponen shift ini memisahkan unsur-unsur pertumbuhan Kabupaten Kediri yang bersifat intern dan ekstern, di mana proportional shift dari pengaruh unsur-unsur luar yang bekerja dalam Provinsi Jawa Timur dan differential shift adalah akibat dari pengaruh faktor-faktor yang bekerja di dalam Kabupaten Kediri.

\section{KESIMPULAN}

Berdasarkan hasil analisis dan pembahasan dapat diambil beberapa kesimpulian sebagai berikut :

Penurunan share sektor Pertanian disebabkan lahan pertanian yang terus menyusut, dan disisi lain produktifitas pertanian juga menurun. Karena sektor Pertanian identik dengan ketahanan pangan, maka penurunan sektor Pertanian yang terus menerus dikhawatirkan akan menyebabkan ketahanan pangan terganggu sehingga mengharuskan impor untuk memenuhinya.

Berdasarkan kriteria LQ (Location Quotion) dapat kita ketahui Kabupaten Kediri surplus akan produk pertanian yang dihasilkan karena nilai LQ selama lima tahun diatas.

Sektor-sektor yang memiliki nilai komponen pertumbuhan proporsional positif, yaitu sektor pertanian, sektor bangunan dan konstruksi, sektor perdagangan, hotel dan restoran, sektor pengangkutan dan komunikasi, dan sektor jasa-jasa. Sedangkan sektorsektor yang mempunyai nilai komponen pertumbuhan 
proporsional negative, yaitu sektor pertambangan dan penggalian, sektor industri pengolahan, dan sektor bank dan lembaga keuangan lainnya

\section{DAFTAR PUSTAKA}

W.W,RostowTeori Pembangunan, Edisi Pertama, Cetakan Pertama, Penerbit, Ekonisia: Yogyakarta.

Annisa Nurfatimah, 2013, AnalisisPotensi sector pertanian kabupaten/Kota Di Provinsi Bali, Skripsi Ilmu Ekonomi Studi Pembangunan, Fakultas Ekonomi, Universitas Islam Negeri Syarif Hidayatullah, Jakarta.

(Suparmoko,2002)Analisis Struktur Perekonomian dan pertanian Ekonomi Di Provinsi BantenMelalui Pendekatan LQ, SHIFT SHARE, Skripsi Ilmu Ekonomi Studi Pembangunan, Fakultas Ekonomi, Universitas Negeri Semarang.
David Ricardo (1772-1823) BPFE, Yogyakarta. Aswandi, $\mathrm{H}$ dan Kuncoro, Mudrajad. 2002. Evaluasi Penetapan Kawasan Andalan: Studi Empiris Di Kalimantan Selatan 1993-1999.

Jurnal Ekonomi dan Bisnis Indonesia, Vol. 17, No. 1, 2002, 27 - 45 . 2003 Erlangga, Jakarta.

Sukamto, 2005. Pusat Statistik kabupaten kediri, 2012. Data PDRB dan perbandingan Provinsi Jawa Timur.

Sukirno,2004; $\quad$ Peningkatan Pendapatan Praeger Publisher, New York and London, Foourt Edition.

Blakely, E. J. 1989. Planning Local Economic Development: Theory and Practice. California: SAGE. Boediono. 1992.

St.Martin.Glasson, John. 1990. Pengantar Perencanaan Regional. Terjemahan Paul Sitohang. Jakarta: LPEUI.

Husaini Usman dan R. Purnomo Setiadi Akbar, 2003. Pengantar Statistika, Bumi Aksara, Jakarta. 